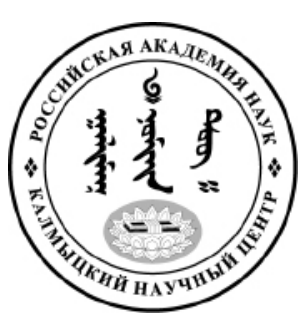

Published in the Russian Federation

Oriental Studies (Previous Name: Bulletin of the Kalmyk Institute for

Humanities of the Russian Academy of Sciences)

Has been issued as a journal since 2008

ISSN: 2619-0990; E-ISSN: 2619-1008

Is. 3, pp. 355-364, 2019

DOI: 10.22162/2619-0990-2019-43-3-355-366

Journal homepage: https://kigiran.elpub.ru

УДК 902.6

\title{
Древнейшая история Предкавказья в свете концепции индоевропейских миграций (часть 1)
}

\author{
Николаева Надежда Алексеевна ${ }^{l}$ \\ ${ }^{1}$ Московский государственный областной университет (д. 10А, ул. Радио, 105005 Москва, Рос- \\ сийская Федерация) \\ кандидат исторических наук, доцент \\ ORCID: 0000-0003-3961-9284 \\ E-mail: nikolaeva3145@yandex.ru
}

Аннотация. Цель статьи - реконструкция древнейшей истории Предкавказья. Maтериальл. В части 1 дана полная информация об уникальном памятнике на территории Предкавказья - Джангар/Улан Толга, курган 1 (Калмыкия, Октябрьский район, пос. Джангар). Meтоды. Использованы как традиционно археологические методы, применяемые при раскопках (стратиграфический, сравнительно-типологический), так и сравнительно-исторический и метод лингво-культурной атрибуции в части интерпретации памятника (часть 2). Результатьл. Показано, что погребения в кургане отражают в хронологической последовательности события миграционного характера в истории Предкавказья эпохи энеолита и бронзового века, связанные с древней историей Центральной и Восточной Европы (часть 1 и 2). Bblводы. Первая, тохарская, миграция отмечена погребениями с зооморфными скипетрами. Вторая миграция, индоиранская, разделяется в Предкавказье на индоариев в западной части (новотитаровский вариант кубано-днепровской культуры с повозками) и праиранцев (древнеямная культура). Третья миграция древнеевропейцев завершилась и выразилась в существования в Предкавказье памятников катакомбной культуры вплоть до прихода племен срубной культуры с востока, которая ознаменовала иранскую реконкисту Степи в XIV-XIII вв. до н. э.

Ключевые слова: энеолит, бронзовый век, Предкавказье, индоевропейские миграции, зооморфные конеголовые каменные скипетры, ямная культура, катакомбная культура

Благодарности. Автор выражает благодарность д-ру ист. наук Марии Александровне Очир-Горяевой за консультацию и ценные замечания по статье.

Для цитирования: Николаева Н. А. Древнейшая история Предкавказья в свете концепции индоевропейских миграций. Oriental Studies. 2019;(3): 355-364. DOI: 10.22162/2619-0990-201943-3-355-364.

UDC 902.6

\section{The Earliest History of Ciscaucasia: a Perspective from the Concept of Indo-European Migrations. Part 1}




\author{
Nadezhda A. Nikolaeva ${ }^{1}$ \\ ${ }^{1}$ Moscow Region State University (10A, Radio Str., Moscow 105005, Russian Federation) \\ Cand. Sc. (History), Associate Professor \\ ORCID: 0000-0003-3961-9284 \\ E-mail: nikolaeva3145@yandex.ru
}

\begin{abstract}
Goals. The study aims to reconstruct a fragment of the ancient history of Ciscaucasia. Materials. Part 1 provides a complete information on an unusual burial complex in Ciscaucasia Dzhangar/Ulan-Tolga mound 1, Kalmykia. Methods. Archaeological methods such as stratigraphic and typological are used to reconstruct the linguistic and cultural situation in the region. Results. The paper shows that burials within the mound indicate a chronological sequence of migrations from Central and Eastern Europe during the Eneolithic and the Bronze Age. Conclusions. The first migration, supposedly a Tocharian one, is evidenced by burials with zoomorphic scepters. The two subsequent migrations, Indo-Iranian ones, can be associated with Indo-Aryans of western Ciscaucasia (Novotitarovka version of the Kuban-Dnieper culture with carriages) and Proto-Iranians of eastern Ciscaucasia (Pit-Grave culture). The third Indo-European migration is mirrored by the Catacomb culture which lasted until the arrival of the Timber-Grave population from the east, apparently evidencing the Iranian Reconquista of the steppe in the 14 th -13 th centuries BC.

Keywords: Eneolithic, Bronze Age, Ciscaucasia, Indo-European migrations, zoomorphic horse-headed stone scepters, Pit-Grave culture, Timber-Grave culture

Acknowledgements: The author expresses deep gratitude to Dr. Maria A. Ochir-Goyaeva for her most valuable comments on the article manuscript and advice in selection of new academic monographs that have recently been published in Kalmykia and deal with the topic under consideration.

For citation: Nikolaeva N. A. The Earliest History of Ciscaucasia: a Perspective from the Concept of Indo-European Migrations. Part 1. Oriental Studies. 2019;(3):355-364. DOI: 10.22162/2619-09902019-43-3-355-364.
\end{abstract}

\title{
है
}

Введение. Территория Калмыкии хорошо исследована в археологическом отношении, благодаря масштабным спасательным археологическим раскопкам в зонах строительства крупных объектов народно-хозяйственного значения советского периода. В те годы были в большом количестве изучены курганные группы с погребениями всех эпох [Очир-Горяева 2008].

Среди этих памятников выделяется целый ряд уникальных памятников, значение которых выходит далеко за пределы республики. Особенно это касается погребальных памятников энеолита - бронзового века III-II тыс. до н. э., которые являются предметом нашего внимания.

В 1984-1987 гг. нами проводились спасательные раскопки курганов в зоне строительства Калмыцко-Астраханской оросительной системы. В 1985 г. были раскопаны 18 курганов из 37 в курганной группе Джангар/Улан-Толга, расположенной в 12 км к востоку от посёлка Джангар Октябрь- ского района и в 6 км к северу от пос. Барун (45.12.25.9 северной широты; 47.17.0.58 восточной долготы $)^{1}$.

Цель статьи состоит в публикации уникального погребального комплекса энеолитической эпохи погребения с каменным зооморфным скипетром ${ }^{2}$ из курганной группы Джангар/Улан-Толга ${ }^{3}$ и рассмотрении его на фоне древнейшей археологической истории предкавказских степей.

Постановка вопроса. Зооморфные (конеголовые) каменные скипетры эпохи энеолита, по мнению многих ученых, сим-

${ }^{1}$ Руководители раскопок - Н. А. Николаева, В. А. Сафронов.

${ }^{2}$ Находки сданы Е. В. Цуцкину, заведующему сектором археологии Калмыцкого научно-исследовательского института истории, филологии и экономики (КНИИИФЭ), а скипетр передан заместителю директора ИА АН СССР В. П. Шилову.

${ }^{3}$ См. отчет Н. А. Николаевой: [НА ИА РАН 2. Ф-1. Д. Р-1. № 10970]. 
волизируют факт доместикации лошади и появления конных пастухов, представляя собой инсигнии власти пастушеской элиты. Они - ключ к решению ряда исторических проблем, например: места и времени перехода к пастушеству; этнокультурной атрибуции первых пастухов в Европе и в евразийских степях; траектории их движения и контактов с автохтонным населением, а также о вкладе в формирование ямной культуры и возможности связи первых миграций пастухов с индоевропейской прародиной.

Основная часть. В настоящее время известно около 40 экземпляров таких скипетров. Серия типологически неоднородная. Первоначально учитывались как скипетры только реалистистические изображения; позднее их классифицировали на реалистические, схематические и абстрактные [Телегин 2000]. Какие из них первичны, а какие вторичны - мнения расходятся, поскольку хронологически эти находки определяются расплывчато в пределах Триполье В-C1 [Дергачев 2007].

Что касается дефиниции «конеголовые», то только суворовский скипетр [Даниленко 1974], без сомнения, изображает голову лошади, что позволило считать и другие скипетры также изображением лошади. Им посвящено большое число работ (В. Н. Даниленко, Д. Я. Телегин, В. А. Дергачев, Н. С. Котова, И. В. Манзура, С. Н. Кореневский), но источник пока себя не исчерпал. Девять скипетров достоверно зафиксированы в слоях поселений трипольской и других земледельческих культур Юго-Восточной Европы [Манзура 2000: 273-295; Дергачев 2007: 95], другие в погребальных памятниках. Лавинообразное увеличение числа скипетров за последние 40 лет не приблизило нас к точной дате и убедительному ответу на поставленные проблемы.

В 1985 г. в кургане 1 группы Джангар/ Улан-Толга (калм. Красный холм) было найдено погребение с зооморфным схематическим скипетром. Включено в Свод археологических памятников Калмыкии под этим названием [Очир-Горяева 2008: рис. 24$]^{4}$.

${ }^{4}$ В наших публикациях памятник идет под названием «Джангар курган 1» [Сафронов 1989; Николаева 2011б].
Первая публикация инвентаря памятника Улан-Толга/Джсангар 1/3 и ее интерпретация сделаны одним из авторов раскопок [Сафронов 1988: 298; Сафронов 1989: 196197, рис. 52]; затем комплекс со скипетром с ошибочным его описанием и под другим названием был опубликован В. П. Шиловым [Шилов 2009: 301, рис. 165].

После этого был частично переопубликован В. Н. Дергачевым со ссылкой на В. П. Шилова как на автора находки [Дергачев 2007: 87, рис. 13].

Описание стратиграфии кургана 1 и его погребений с неверным определением древнейшего погребения (таковым названо погребение 8 вместо погребения 3) под новым названием Улан-Толга комплекс опубликован Н. И. Шишлиной [Шишлина 2007: 31, 32].

Наибольшую путаницу в чехарду публикаций этого памятника внес С. Н. Кореневский, который включил в свою монографию комплекс и как Джсангр 1/3, и как Улан-Толга $1 / 3$, опираясь на публикацию В. П. Шилова, добавив комментарии Д. Я. Телегина 2000 г. к описанию комплекса Джангар 1/3 в Отчете Н. А. Николаевой 1986 г. без ссылки на Отчет [Кореневский 2012: 34, рис. 32].

Как и следовало ожидать, никаких даже после этих публикаций прорывных решений в интерпретации этого уникального комплекса со скипетром не возникло. Это стало для нас поводом вернуться к вопросу о полной публикации памятника и определению его места в древней истории Предкавказья и Европы.

Полное освещение стратиграфии памятника Джсангар/Улан-Толга, курган № 1 (рис. 1) имеет исключительно важное значение, поскольку в нем был найден единственный из всех известных 40 находок комплекс с конеголовым схематическим скипетром, стратиграфически соотнесенный с синхронными энеолитическими погребениями Северного Причерноморья и Предкавказья, содержащими керамику, и стратиграфически связанный со следующим по времени погребением кубано-днепровской культуры раннебронзового века с повозкой, входящей в древнеямную культурно-историческую область. Таким образом, объекты в кургане характеризуют смену трех эпох в археологической истории бронзового века степей Предкавказья и Азово-Черноморских степей. 


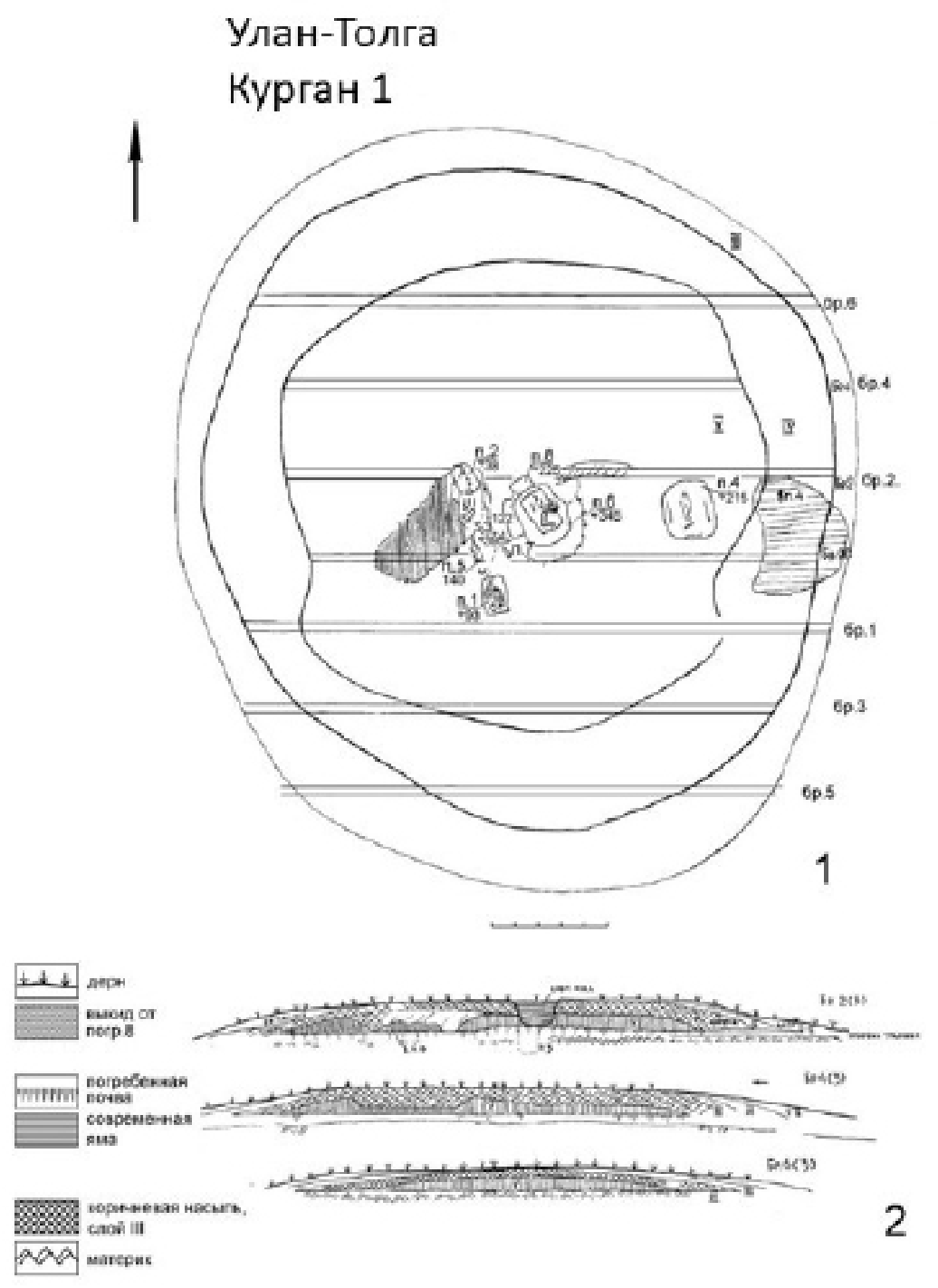

Puc. 1. Погребения энеолита/бронзового века в кургане 1 могильника Джангар/Улан-Толга (северо-восток Предкавказья)

1 - план кургана №1; 2 - бровки 2,4.6;

Все насыпи кургана относятся к более позднему, чем скипетр, времени, и погребение № 3 со скипетром непосредственного отношения к этим насыпям не имеет, но является древнейшим объектом в кургане. Назвать его согласно существующей терминологии «основным погребением» было бы неточно, поскольку он был перекрыт выкидом из собственной могилы, а не насыпью, поэтому скорее принадлежит к грунтовым или холмовым погребениям.

Дата terminus ante quem для скипетра связана с курганным погребением № 6, поэтому погребение № 3 все-таки связано со стратиграфией кургана, на которой следует остановиться особо и которая и сама по себе является, помимо предметов инвентаря, важным историческим источником.

Диаметр кургана - 46 м. Высота 1,46 м до современной и 1,8 м - до древней дневной поверхности. Курган исследовался с помощью скрепера с оставлением 4-х бровок - разрезов кургана. Самой информативной была бровка 2, а все погребения находились в траншее 0-2.

Бровка 2 (восточная сторона) (рис. 1) длиной 34 м. Высота до погребенной почвы - 1,3 м, высота до дна траншеи - 1,8 м. В бровке 2 (восточная сторона) прослеживалось 5 слоев. Нумерация слоев сверху вниз.

I слой - дерн $(10 \mathrm{~cm})$. II слой связан с сооружением могилы № 4, определяемой 


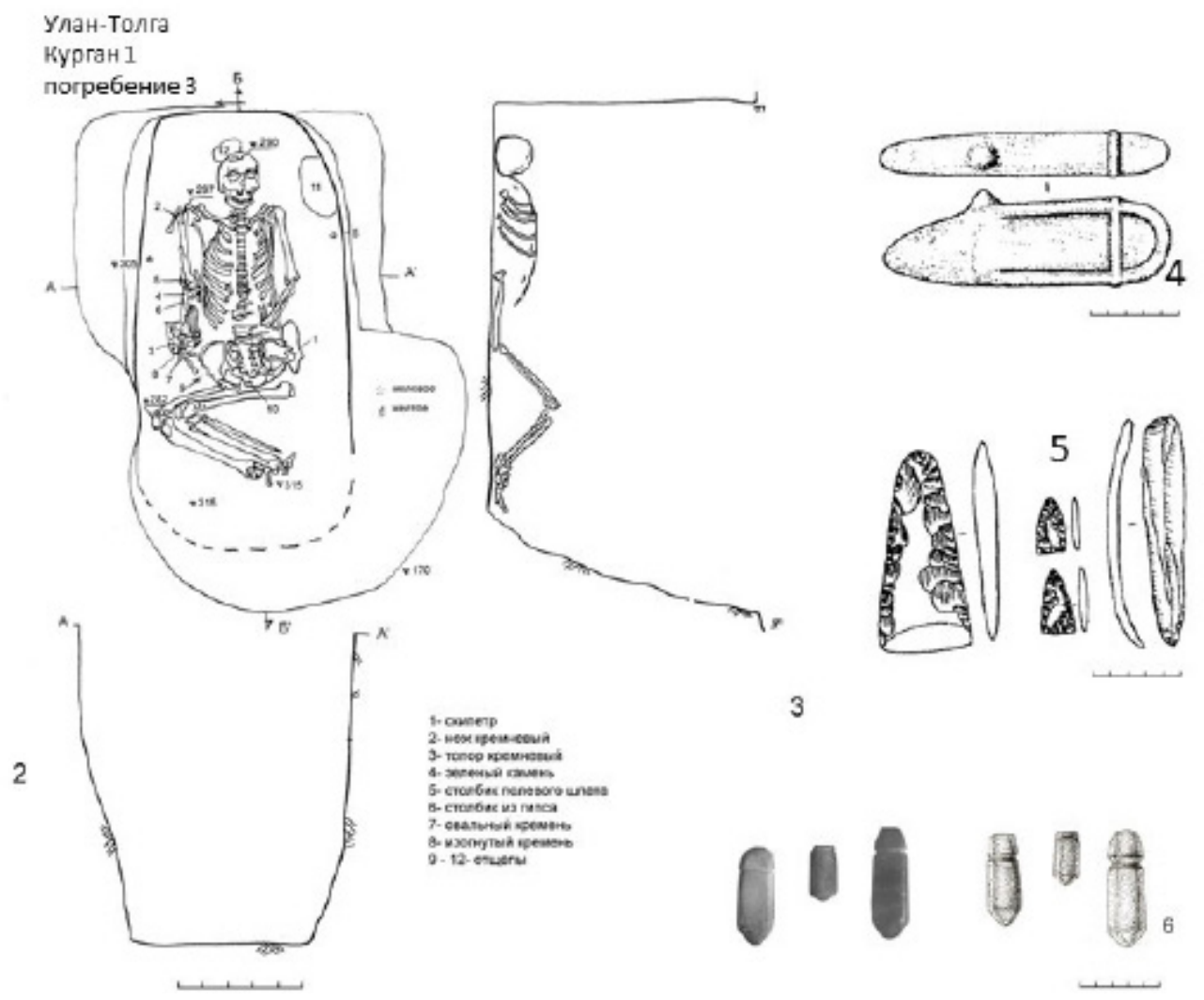

Рис. 2. Могильник Джангар/Улан-Толга, курган 1, погребение 3

выкидом от нее в двух бровках). III слой законсервировал выкид от могилы № 6 . IV слой длиной 27 м, высотой по центру 0,7 м законсервировал сложный выкид от погребений 7 или 8 (полевое обозначение выкида - Va).

$\mathrm{V}$ слой - смешанный - из материкового суглинка и древней погребенной почвы зеленого цвета. Длина - 13 м. Мощность - 0,6 м. Был «насыпан» над погребением № 3 (со скипетром). По центру бровки 2 просматривается небольшое всхолмление на погребенной почве высотой 10 см, длиной 3 м, которое можно считать выкидом от погребения 3. Хотя погребение № 3 найдено в кургане 1, но подкурганным его можно считать условно. Однако оно было древнейшим в кургане по отношению ко всем объектам кургана.

Стратиграфия кургана представлена как прямой стратиграфией, так и стратиграфией выкидов и определяет последовательность и относительную хронологию погребений. Порядок захоронений в кургане определялся по стратиграфии слоев (бровка 0 и 2) и подтверждался прямой стратиграфией могил $(№$ 6, 7, 8). Погребения № 1, 2 в насыпи (скорченные на боку с руками перед лицом, без инвентаря) относились к позднебронзовому веку. Погребение № 5 относилось к средневековью. Погребения № 3, 7, 8 (в материке) относились к энеолиту/раннебронзовому веку. Погребения № 4 и № 6 (с повозкой) относились к раннебронзовому веку (план кургана - рис. 1: 1).

Обстоятельства обнаружения древнейшего погребения № 3 (со скипетром) интригующие. Курган в древности был выше, но вершина его была срезана под геодезическую вышку. Через центр с самой вершины до материка прошла современная яма траншейного типа, разрушившая центр кургана. Погребение 3 находилось в траншее 0-2 по центру кургана. Первоначально за пятно заполнения могилы № 3 было принято ложное пятно - срез этой современной ямы, имевший в плане прямоугольные очертания.

По мере углубления пятно меняло размеры и, наконец, исчезло на материке, на глубине 1,6 м от условного центра. Дальнейшее прокапывание было продолжено вслепую, только руководствуясь контуром исчезнувшего ложного пятна до появления вертикально стоящих берцовых костей скелета на глубине 2,77 м от 0. 
Поскольку заполнение могилы № 3 не отличалось ни по цвету, ни по плотности от материкового дна траншеи от скрепера, что представляло бы ориентир в поисках реального контура, верхний контур могилы имеет неправильные очертания (рис. 2:1). Только на глубине 3,05 м от 0 могила приобрела ясные очертания, и этот контур можно считать истинным. Размеры ямы по дну 1,80 х 0,87 х 1,45 м (указана истинная глубина ямы от нижней границы погребенной почвы; глубина дна могилы от $0-3,15$ м) (рис. 2: 1-3).

Скелет мужчины, 55-65 лет, был погребен по «древнеямному обряду» на спине, ноги поставлены на стопы и почти сохранили положение коленями вверх (рис. 2: 3).

Хотя трудно представить, чтобы не было никакого настила над могилой, но земля быстро заполнила могилу и создала опору для сохранения ног на стопах в вертикальном положении. Головой скелет был ориентирован на восток, имел отличную сохранность. При слепом прокапывании лопатой задели череп, поэтому этот скол на черепе не связан с какой-либо травмой древности, как писали публиковавшие его авторы, а имеет современное происхождение. Череп имел особую иенность и привлек внимание антропологов (см. ниже). № 3

Погребальный инвентарь погребения

1. Слева под костями таза лежал так называемый конеголовый «схематический» скипетр из диорита. Длина скипетра 19,9 см, ширина -6 см, толщина $-3,06$ см. Два валика на отшлифованной поверхности скипетра являются обозначением конской узды (рис. 2: 4).

2. У правого плеча находилась ножевидная пластина из желто-коричневого кремня, хорошо отретушированная с одного края; длиной 15,7 см; шириной 3,5 см (рис. 2: 5).

3. У правой лучевой кости - клиновидный топор с закругленной торцовой частью, из того же кремня, тщательно отретушированный с двух сторон с заполированным лезвием (длина $-13,7$ см, ширина $-6,9$ см, толщина $-1,5$ см) (рис. 2: 5).

4. Вокруг головы и слева от скелета в заполнении и на дне отмечены стрелы из серого молочного кремня с двусторонней ретушью, размером 4,3 см и 3,8 см, а также около 70 отщепов, микролитических орудий (рис. 2: 5).
5. Справа у локтя лежали три идола в виде призматических столбиков. Их верхняя (меньшая) часть была выделена желобком, а нижняя часть имела пирамидальное окончание. Один столбик был изготовлен из ортоклаза. Длина его - 7,3 см. Два других сделаны из серого камня длиной 6,5 см и 3,8 см (один столбик обломан по желобку) (рис. 2: 6).

Хотя точные аналогии этим идолам до сих пор не найдены, можно отметить сходство с символом плодородия и возрождения - фаллическими идолами в культуpe Гумельница, т. е. там же, где находили и зооморфные скипетры, а также в синхронных памятниках Италии, Иллирии, на Мальте. Их дата — конец IV тыс. [Гимбутас 2006: 180, 184, 288].

Погребение № 6 (рис. 3).

Занимало южную половину траншеи 0-2. Сначала представляло собой большое, неправильной формы пятно в поперечнике 6 м на глубине 1,2 м от условного нуля. Впущено с IV слоя, перекрыто III слоем. Прямая стратиграфия обозначилась в виде асимметрии пятна, которая возникла за счет слияния пятен могил № 7 и 8 , к северу и востоку от могилы № 6, примыкавших к могиле 6 (рис. 3: 3).

На уровне материка были зафиксированы уже другие размеры площади могилы 4,0 х 3,5 м, которые были уменьшены заплечиками на 1,2 м и не менялись. Глубина могилы от настила $-1,8$ м. Могила была перекрыта тростниковым настилом, следы от которого прослеживались по периметру. Настил, закрывавший могилу 6 (тлен бело-сиреневого цвета), перекрывал и пятна погребений 7 и 8 , тем самым зафиксировал прямой стратиграфией большую древность № 7 и 8 . (рис. $3: 3$ ).

Описание повозки

Под настилом лежали фрагменты деревянной конструкции повозки. С южной стороны, под настилом, ниже края могилы на 0,7 м находились пологие заплечики (шириной 1,2 м), на которых наклонно лежало одно колесо диаметром 0,6 м со ступицей диаметром 0,2 м. Колесо стояло на «подушке» из чистейшего желтого нетронутого суглинка по всей площади могилы. Это заполнение могилы производило впечатление, что мы вышли на дно могилы с 


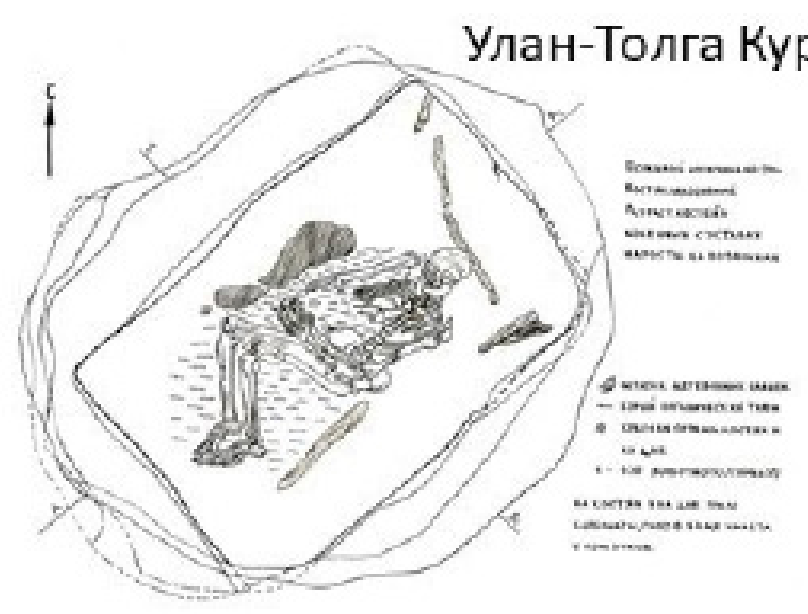

ган 1 погребение 6
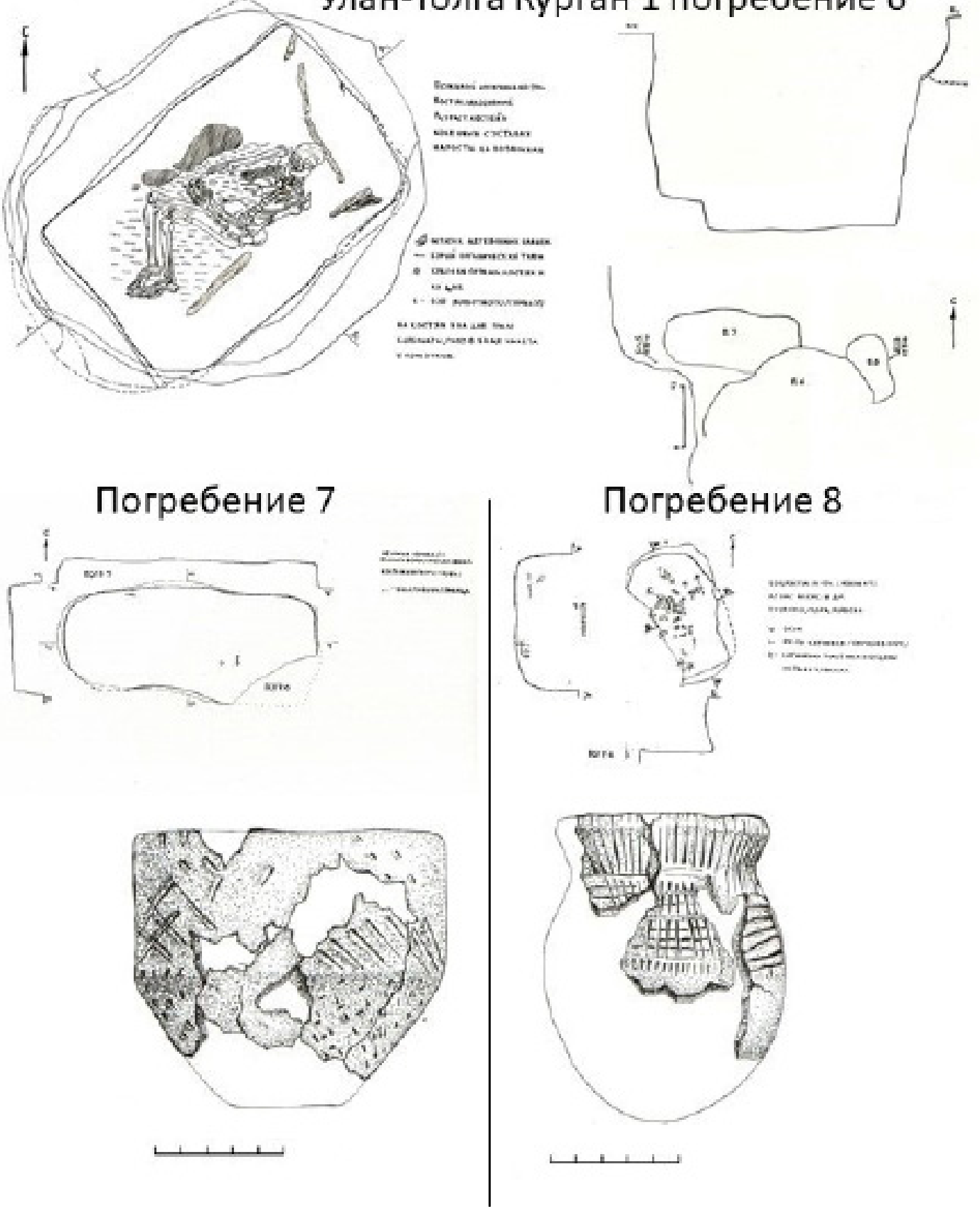

Puc. 3 Джангар/Улан-Толга, курган 1, погребения 6,7,8

1 - план погребения 6 с повозкой

3 - стратиграфия пятен от могил $6,7,8$

2 - разрез могилы 6

5 - сосуд-кубок из погребения 7

4 - погребение 7

7 - сосуд из погребения 8

отсутствующим скелетом. Прокопав еще на 1,5 м, наткнулись на кости скелета, который также лежал в обрамлении частей рамы повозки.

Инвентарь погребения № 6. На настиле была обнаружена кремневая пластинка из желтого кремня длиной 3 см.
6 - погребение 8

Инвентарь погребения № 8 в могиле № 6. В заполнении могилы сразу под настилом у восточной стенки на этом же уровне были обнаружены кости скелета ребенка из погребения № 8, задетого и частично разрушенного могилой № 6. Предметы, положенные на настил с ними, были те же, что и при 

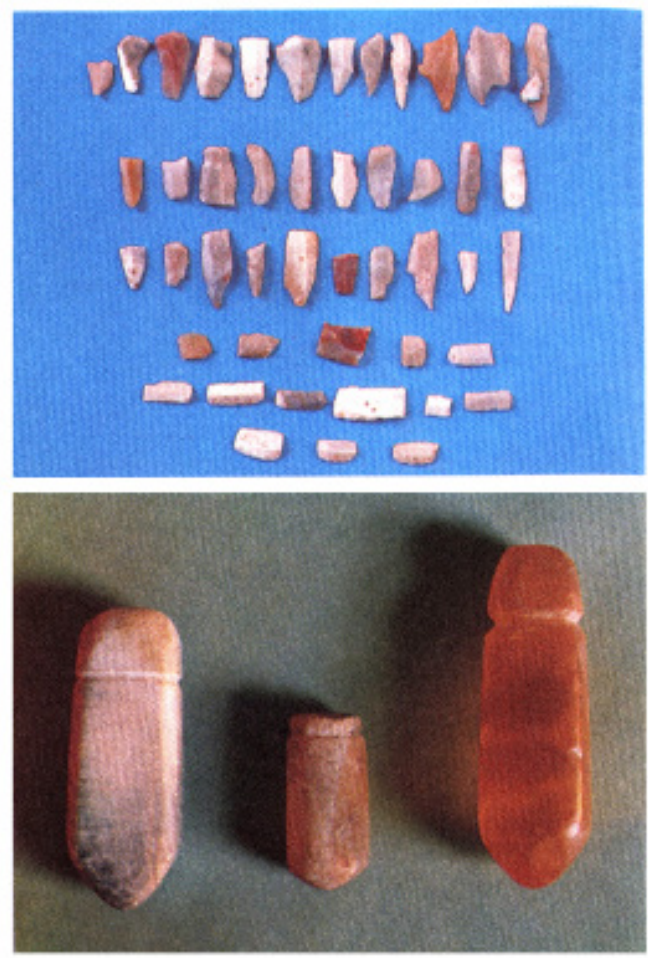
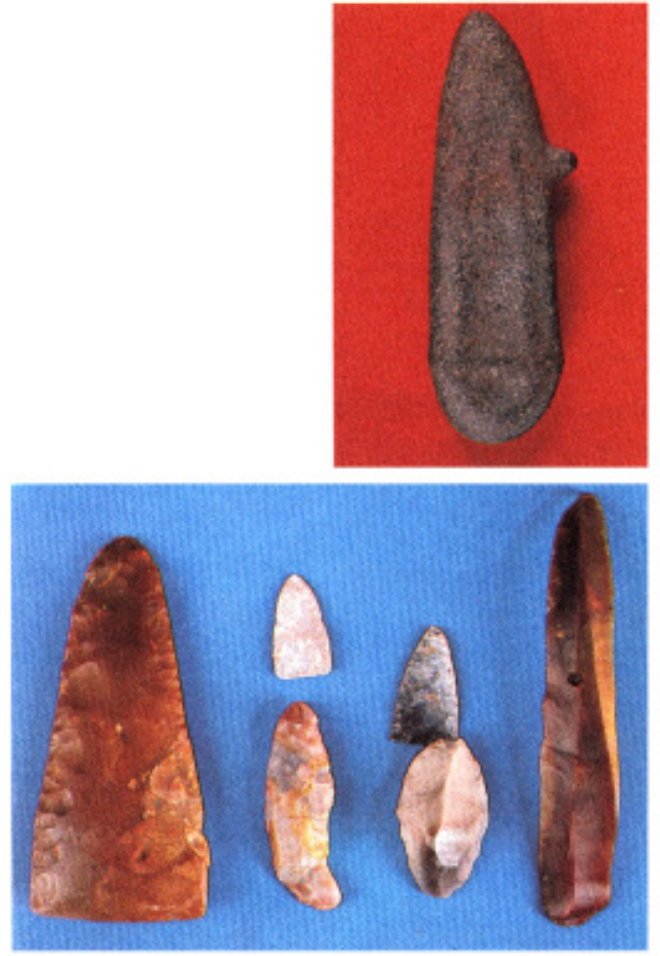

Рuc. 4. Фото комплекса предметов из погребения № 3 кургана 1 (Джангар/Улан-Толга, Калмыкия)

погребении 3, а именно: микролитические пластинки и отщепы, а также фрагмент полного профиля сосуда.

Сосуд был орнаментирован по венчику и плечевой части. Разрушенное погребение 8 было и ранее видно в виде выступа асимметричного общего пятна от трех могил (рис. 3: 3).

На глубине 3,4 м от условного нуля лежал скелет мужчины 60-70 лет, окрашенный охрой и посыпанный мелом, на правом боку с отклонением на спину, головой на северо-восток. На погребенном был тлен черного цвета от покрывала, а на нем - слой белого мела и охры. У восточной стенки лежали кости собаки.

Культурная атрибуция погребения № 6 в отсутствие инвентаря устанавливается по обряду положения на спине с поворотом на бок (что обеспечивалось поддерживающей «подушкой» из глины). Этот обряд - главный признак кубано-днепровской культуры, синхронной и генетически родственной древнеямной культуре, отличающий ее от древнеямной культуры. Другой критерий кубано-днепровской атрибуции связан с инвентарем - повозкой или ее деталями, как в данном случае, с колесом и рамой [Николаева 2007: 3 и сл.] $]^{5}$.

Погребение № 8 (рис. 3: 6, 7).

Как следует из описания погребения № 6, часть погребения № 8 оказалась в могиле 6, а часть оставалась in situ. Погребение

${ }^{5}$ Впервые мы отделили кубано-днепровскую культуру от остальных древнеямных памятников и определили ее лингвистическую атрибуцию как индоарийскую [Николаева 1980: 29,30; Николаева 2007]. Выделенную нами культуру А. Н. Гей переименовал позднее в новотитаровскую, имеющую проявления только в Западном Прикубанье, поэтому в археологической литературе бытуют два названия одной культуры. В широком смысле слова кубано-днепровская культура - культура индоарийских мигрантов, которые по ходу движения из Центральной Европы делали остановки в низовьях рек, образуя анклавы. Такие анклавы есть в Нижнем Поднепровье (старосельская группа древнеямной культуры, по Ю. А. Шилову) и в Нижнем Прикубанье (новотитаровская культура, по А. Н. Гею). В Восточном Предкавказье был найден в Улан Толга 1/6 комплекс кубано-днепровской культуры с повозкой впервые с ясной стратиграфической позицией относительно погребения с конеголовым скипетром. 
подростка было разрушено при сооружении могилы № 6. Настил от погребения 6 перекрывал и могилу 8. Выкид от погребения 8 незначительной мощности в виде линзы коричневого суглинка фиксировался в бровке 2 (восточная сторона, см. выше). Судя по размерам могилы $(0,95 \mathrm{x} 0,55 \mathrm{~m})$, это было скорченное погребение подростка, на левом боку, ориентировано головой на ЮЮВ; окрашено охрой.

\section{Инвентарь}

1. По дну могилы были разбросаны кремневые отщепы и микролиты, которые соответствовали тем, которые были встречены в заполнении могилы № 6 и в могиле № 3 (рис. 3: 6).

2. Фрагменты керамики, которые были выявлены в заполнении могилы № 6, подходили к фрагментам сосуда, оставшиеся в первоначальном положении in situ в погребении № 8, и составили единый профиль круглодонного сосуда черного цвета (рис. 3: 7). Мешковидная форма насечки по венчику сосуда сближает его с сосудом из погребения Архара 27/2 [Синицын, Эрдниев 1966; Шишлина 2007: 27, рис. 8].

Орнамент на сосуде сближает его с позднесреднестоговским сосудом из погребения 4 кургана 31/7, хутор Попов [Котова 2006: 304, рис. 82].

\section{Погребение № 7}

Было обнаружено одновременно в общем пятне заполнения могил № 6 и 8. Пятно могилы 7 подходило с севера к могиле 6 и перекрывалось последней. Размеры могилы: 1,95 х 0,85 м. Исследованная глубина могилы - 0,2 м. На дне могилы была найдена кость животного, фаланга пальца взрослого человека и обломки черепа. Погребение (вероятно, вытянутое) было разрушено.

\section{Инвентарь}

На выкиде из могилы № 6 лежал сосуд из погребения № 7 - орнаментированный черноглиняный кубок с цилиндрической верхней частью и меньшей по размеру конической придонной частью и несохранившимся дном, однако орнамент в виде пунктирного зигзага от венчика до дна по всему тулову, дополненный оттисками «шагающей гребенки» на придонной части сосуда, идентичен такому же орнаменту на сосудах ямной культуры фазы Михайловка II, [Даниленко 1974: 80, рис. 49: 5, 6], а также орнаменту сосудов дериевской культуры [Котова 2006] (рис. 3: 7).

\section{Выводы}

Анализ стратиграфии памятника показывает, что погребение № 3 и погребения № 7,8 - если и не синхронны, то близки по времени. Культурная атрибуция погребений № 8, как позднесреднестоговская, определяется аналогиями круглодонному сосуду в керамике энеолитического Хвалынского могильника (рис. 3: 7), а также аналогиями в сосудах из Прикубанья [Даниленко 1974: рис. 42]. Но более яркими представляются аналогии орнаменту - насечки на венчике и метопы в виде решетки по плечевой части - в декоре среднестоговского сосуда из подкурганного захоронения № 4, Попов 31/7 [Даниленко 1974: 70, рис. 44: 11; Котова 2006: рис. 82], которое определяется поздним периодом культуры Средний Стог II, по В. Н. Даниленко. Кроме того, в Улан-Толге повторяется ситуация сосуществования вытянутых и скорченных захоронений, как и в погребении 7 кургана 1, со скипетром в Суворово [Даниленко 1974, рис. 48: 8; 49: 5].

Все три погребения предшествуют погребению № 6 с повозкой, атрибуция которой связана с кубано-днепровской культурой, синхронной древнеямной культуре понто-каспийских степей [Николаева 2007: 3 сл.]. В отсутствие инвентаря критерием для культурной атрибуции погребения № 6 являются элементы повозки в могиле.

Стратиграфия кургана Джангар/ Улан-Толга 1 устанавливает последовательность «новоданиловская культура со скипетрами» $\rightarrow$ позднесреднестоговские памятники $\rightarrow$ кубано-днепровская, синхронная древнеямным памятникам по присутствию в них костяных молоточковидных булавок, что служит дополнением к культурно-хронологической периодизации памятников Северо-Восточного Предкавказья, разработанной В. А. Сафроновым на основе раскопок И. В. Синицыным и У. Э. Эрдниевым курганов в Калмыкии [Сафронов 1974]. Эта периодизация хорошо отражала последовательность массовых памятников бронзового века Калмыкии. Согласно этой схеме, древнейшими в курганах были безынвентарные погребения по древнеямному обряду, в том числе и со скипетром (Архара 27) ния финального этапа древнеямной культу-

${ }^{6}$ Курганная группа «Архара» (Архаринский могильник), курган 27. 
ры содержали сосуды, объединяющие их с другими древнеямными памятниками понто-каспийских степей, а также и костяные молоточковидные булавки.

Далее, по периодизации В. А. Сафронова, следуют две одновременные группы ранних катакомбников с вытянутым обрядом и с древнеямным обрядом захоронения и костяными молоточковидными булавками. Их сменили классические катакомбы с курильницами и охристыми сосудами, а затем - катакомбы со срубным обрядом (скорченно на боку и руками перед лицом) и инвентарем (реповидные сосуды, срубоидные ножи). Последними были погребения срубной культуры, представлены в кургане в виде погребения № 1 и 2.

Краниологический материал из погребения Джангар/Улан-Толга 1/3 имеет важное значение, поскольку позволяет подтвердить две генеалогические линии развития энеолита и раннебронзового века в степях Евразии, что ранее было высказано археологами [Даниленко 1974]. Череп имел превосходную сохранность, был передан антропологу А. В. Шевченко в 1985 г. и повторно проанализирован А. А. Казарницким, который дал заключение: «Получил подтверждение вывод А. В. Шевченко о том, что черепа ямной культуры Калмыкии и Астраханской области отличаются от всех известных краниологических серий ямной культурно-исторической общности. По всей видимости, такой морфологический комплекс имеет автохтонное энеолитическое или еще более раннее происхождение» [Казарницкий 2012: 180]. Позднее он уточнил: «Таким образом, эти черепа демонстрируют черты как неолитических, так и при-

\section{Источники}

НА ИА РАН 1 - Научный архив Института археологии РАН. Николаева Н. А. Исследование курганной группы у с. Джангр Октябрьского района Калмыцкой АССР в 1985 г. Ф-1. Р-1. № 10969 (отчет). № 10969а (альбом иллюстраций к отчету).

НА ИА РАН $2-$ Научный архив Института археологии РАН. Николаева Н. А. Исследование курганов в зоне строительства Калмыцко-Астраханской рисовой оросительной системы (КАРОС) на землях совхоза «Джангр» Октябрьского района Калмыцкой каспийских ямных групп» [Казарницкий 2014: 148]. Это отделяет памятник Джангар/Улан-Толга1/3 от другого популяционного пласта, включающего среднестоговско-хвалынские памятники (Джангар/Улан Толга 1/8) и другие группы древнеямного населения Северного Причерноморья. Эти выводы, как и рассмотренный нами памятник Джангар/Улан-Толга, курган 1, важны для уточнения происхождения афанасьевской культуры, что подтверждают другие антропологи: «Населению афанасьевской культуры, по-видимому, „изначально“ был присущ определенный краниологический полиморфизм, истоки которого находятся на территории Восточной Европы в материалах культурных образований эпох энеолита (т. е. Джангар/Улан Толга 1/3 [курсив мой. - H. H.]) и ранней бронзы восточноевропейских степей» [Солодовников 2006: 13; Хохлов и др. 2016]

Чтобы определить лингвокультурную атрибуцию уникального памятника Джангар/Улан-Толга, курган 1, погребение 3 и воссоздать картину исторического развития степей Евразии, нужно обратиться к современным концепциям индоевропейских прародин и индоевропейских миграций. Те немногие исследователи, которые пытались объяснить происхождение зооморфных скипетров в рамках индоевропейской концепции, относили подобные памятники к миграции тохар, причем лингвокультурную атрибуцию афанасьевской культуры определяли как тохарскую [Даниленко 1974; Гимбутас 2006; Mallory 1989; Сафронов 1989]. Обоснованность этих гипотез мы рассмотрим в части 2 .

АССР в 1985 г. Ф-1. Д. Р-1. № 10970 (отчет). № 10970а (альбом иллюстраций к отчету).

\section{Sources}

Scientific Archive, Institute of Archaeology of the RAS. Nikolaeva N. A. [Investigating a Mound Group Located next to the Village of Dzhangar, Oktyabrsky District of the Kalmyk ASSR: a 1985 report]. Fond 1. File P-1. No. 10969 (report). No. 10969a (collected illustrations to the report). (In Russ.)

Scientific Archive, Institute of Archaeology of the RAS. Nikolaeva N. A. [Investigating 
Mounds on the Construction Site of KalmykiaAstrakhan Rice Irrigation System within Lands of Dzhangar Collective Farm, Oktyabrsky District of the Kalmyk ASSR: a 1985 report]. Fond 1. File P-1. No. 10970 (report). No. 10970a (collected illustrations to the report). (In Russ.)

\section{Литература}

Даниленко 1974 - Даниленко В. Н. Энеолит Украины. Киев: Наукова думка, 1974. 175 с.

Гимбутас 2006 - Гимбутас М. Цивилизация Великой богини: мир Древней Европы. М.: РОССПЭН, 2006. 572 c.

Дергачев 2007 - Дергачев B. A. О скипетрах, о лошадях, о войне. СПб.: Нестор-История, 2007. 487 c.

Казарницкий 2012 - Казарницкий $A$. А. Население Азово-Каспийских степей в эпоху бронзы (антропологический очерк). СПб.: Наука. 2012. $264 \mathrm{c}$.

Казарницкий $2014-$ Казарницкий A. A. О краниологических особенностях носителей ямной археологической культуры Северо-Западного Прикаспия // Археология, этнография и антропология Евразии. 2014. № 1 (57). C. $142-149$.

Кореневский 2012 - Кореневский С. Н. Рождение кургана. М.: Таус, 2012. 246 с.

Котова 2006 - Котова Н. С. Ранний энеолит Степного Поднепровья и Приазовья. Луганск: Восточноукр. нац. ун-т им. В. Даля, 2006, $327 \mathrm{c}$.

Манзура 2000 - Манзура И. В. Владеющие скипетрами // Археология и культурная антропология (Stratum plus). № 2. Кишинев: Высшая антропологическая школа, 2000. C. 273-295.

Николаева 2007 - Николаева Н. А. Индоарии на Северном Кавказе (III-II тыс.) // Вестник Московского государственного областного университета. Серия: История и политические науки. 2007. № 1. С. 3-26.

Николаева 2011а - Николаева Н. А. Юго-Восточная Европа и Кавказ: культурно-исторические связи в середине III тыс. до н. э. (Проблема датировки конеголовых скипетров). Вестник Московского государственного областного университета. Серия: История и политические науки. 2011. № 1. С. 99-109.

Николаева 20116 - Николаева Н. А. Этнокультурные процессы на Северном Кавказе в III-II тыс. до н. э. в контексте древней истории Европы и Ближнего Востока. М.: Изд-во МГОУ, 2011. $536 \mathrm{c}$.

Очир-Горяева 2008 - Очир-Горяева М. A.
Археологические памятники Волго-Манычских степей (свод памятников, исследованных на территории Республики Калмыкия в 1929-1997 гг.). Элиста: Издат. дом «Герел», 2008. 298 с.

Сафронов 1974 - Сафронов В. А. Классификация и датировка памятников бронзового века (часть 1) // Вопросы охраны, классификации и использования археологических памятников. (Сообщения НMC). Вып. VII. М.: Знание, 1974. С. 24-307.

Сафронов 1988 - Сафронов В. А. О трех прародинах индоевропейцев // Новое о Древнем Востоке (на араб. яз.). М.: Прогресс, 1988. $572 \mathrm{c}$.

Сафронов 1989 - Сафронов В. А. Индоевропейские прародины. Горький: Волго-Вятск. кн. изд-во. 1989. 398 с.

Синицын, Эрдниев $1966-$ Синицын И. В., Эрдниев У. Э. Новые археологические памятники на территории Калмыцкой АССР (по раскопкам 1962-1963 гг.). Элиста: Калм. кн. изд-во, 1966. 183 с.

Солодовников 2006 - Солодовников К. Н. Население горного и лесостепного Алтая эпохи ранней и развитой бронзы по данным палеоантропологии: автореф. дис. ... канд. ист. наук. Барнаул, 2006. 25 с.

Хохлов и др. 2016- Хохлов А. А., Солодовников К.Н., Рыкун М.П., Кравченко Г.Г., Китов Е. П. Краниологические данные к проблеме связи популяций ямной и афанасьевской культур Евразии начального этапа бронзового века // Вестник археологии, антропологии и этнографии. 2016. № 3 (34). C. $86-106$.

Телегин 2000 - Телегин Д. Я. К вопросу о типологии, хронологии и культурной принадлежности скипетров медного века Юго-Восточной Европы и Восточной Европы // Российская археология. 2000. № 3. С. 18-29.

Шилов 2009 - Шилов В. П. Древние скотоводы калмыцких степей. Элиста: Герел, 2009. $304 \mathrm{c}$.

Шишлина 2007 - Шишлина Н. И. Северо-Западный Прикаспий в эпоху бронзы (VIII тыс. до н. э.). М.: изд-во ГИМ, 2007. 400 с. Mallory 1989 - Mallory J. P. In Search of the IndoEuropeans. Language, Archaeology and Myth. London: Thames \& Hudson, 1989. 288 p.

\section{References}

Danilenko V. N. [The Eneolithic in Ukraine]. Kiev: Naukova Dumka, 1974. 175 p. (In Russ.)

Dergachev V. A. [About Scepters, Horses and War]. St. Petersburg: Nestor-Istoriya, 2007. 487 p. (In Russ.) 
Gimbutas M. [The Civilization of the Goddess (of Old Europe)]. Moscow: ROSSPEN, 2006. 572 p. (In Russ.)

Kazarnitsky A. A. [The Population of the AzovCaspian Steppes in the Bronze Age: an Anthropological Essay]. St. Petersburg: Nauka. 2012. 264 p. (In Russ.)

Kazarnitsky A. A. On the biological distinctness of the Pit-Grave (Yamnaya) people in the Northwestern Caspian: cranial evidence. Archaeology, Ethnology \& Anthropology of Eurasia. 2014. No. 1 (57). Pp. 142-149. (In Russ.)

Khokhlov A. A., Solodovnikov K. N., Rykun M. P., Kravchenko G. G., Kitov E. P. Craniological data on the problem of relationship between populations of the Early Bronze Age: Yamnaya and Afanasyevo cultures. Vestnik Arheologii, Antropologii i Ehtnografii. 2016. No. 3 (34). Pp. 86-106. (In Russ.)

Korenevsky S. N. [The Birth of the Mound]. Moscow: Taus, 2012. 246 p. (In Russ.)

Kotova N. S. [The Early Eneolithic in Steppe Zones of Dnieper and Azov Regions]. Lugansk: Dahl East Ukrainian National Univ., 2006. 327 p. (In Russ.)

Mallory J. P. In Search of the Indo-Europeans. Language, Archaeology and Myth. London: Thames \& Hudson. 1989. 288 p. (In Eng.)

Manzura I. V. 'Those who possess scepters'. Archaeology and Cultural Anthropology (Stratum Plus). No. 2. Kishinev: High Anthropological School, 2000. Pp. 273-295. (In Russ.)

Nikolaeva N. A. [Ethno-Cultural Processes in the North Caucasus in the $3^{\text {rd }}-2^{\text {nd }}$ Millennium BC: a Perspective from the Ancient History of Europe and the Near East]. Moscow: Moscow Region State Univ., 2011. 536 p. (In Russ.)

Nikolaeva N. A. Indo-Aryans in the North Caucasus: $3^{\text {rd }}-2^{\text {nd }}$ millennium BC. Bulletin of the Moscow
Region State University. Ser. 'History and Political Sciences'. 2007. No. 1. Pp. 3-26. (In Russ.)

Nikolaeva N. A. Southeast Europe and the Caucasus: cultural and historical ties in the mid- $3^{\text {rd }}$ millennium BC (dating horse-headed scepters). Bulletin of the Moscow Region State University. Ser. 'History and Political Sciences'. 2011. No. 1. Pp. 99-109. (In Russ.)

Ochir-Goryaeva M. A. [Archaeological Monuments of the Volga-Manych Steppes: Collected Descriptions of Monuments Investigated in the Territory of the Republic of Kalmykia between 1929 and 1997]. Elista: Gerel, 2008. 298 p. (In Russ.)

Safronov V. A. [Indo-European Ancestral Homelands]. Gorky: Volga-Vyatka Book Publ., 1989. 398 p. (In Russ.)

Safronov V. A. Classifying and Dating Bronze Age Monuments (Part' 1). In: [Questions of Preservation, Classification and Use of Archaeological Monuments]. Vol. VII. Moscow: Znanie, 1974. Pp. 24-307. (In Russ.) Shilov V. P. [Ancient Livestock Breeders of Kalmyk Steppe]. Elista: Gerel, 2009. 304 p. (In Russ.)

Shishlina N. I. [The Northwestern Caspian Region in the Bronze Age: $5^{\text {th }}-3^{\text {rd }}$ Millennium BC]. Moscow: GIM, 2007. 400 p. (In Russ.)

Sinitsyn I. V., Erdniev U. E. [New Archaeological Excavations in the Kalmyk USSR: 1962-1963]. Elista: 1966. (In Russ.)

Solodovnikov K. N. [Early-to-Mid Bronze Age Heritage of the Mountainous and Forest-Steppe Zones of the Altai: Paleoanthropological Evidence]. A Cand.Sc. (history) thesis abstract. Barnaul, 2006. 25 p. (In Russ.)

Telegin D. Ya. Revisiting typology, chronology and cultural background of Copper Age scepters from Southeast and Eastern Europe. Russian Archaeology. 2000. No. 3. Pp. 18-29. (In Russ.) 